\title{
Brainstem auditory evoked potential abnormalities in myelomeningocoele in the older child
}

\author{
T B DOCHERTY, A G HERBAUT, E M SEDGWICK MD \\ From the Wessex Neurological Centre, Southampton, UK
}

SUMMARY Brainstem auditory evoked potentials and clinical findings were examined in 18 children over the age of 5 years who were born with myelomeningocoele which was closed at birth, and whose hydrocephalus was managed by long term shunting in most of them. The potentials were compared with age and sex matched normal subjects and with four patients with hydrocephalus only. All but one had an abnormal brainstem auditory evoked potential with $72 \%$ showing a delay in the III-V and I-V interpeak latencies of more than three standard deviations. It is proposed that the abnormalities are a reflection of brainstem dysgenesis which is part of an associated ArnoldChiari malformation, though the malformation was clinically asymptomatic in all. The usefulness of the brainstem auditory evoked potential for assessing the course of hydrocephalus and for predicting symptomatic Arnold-Chiari malformation is questioned.

A group of hydrocephalic children born with spina bifida aperta and myelomeningocoele which was closed at birth and who are now over 5 years of age, have had their brainstem function tested by means of the brainstem auditory evoked potential. There have been previous studies of the brainstem auditory evoked potential on neonates with hydrocephalus ${ }^{12}$ and on a group of hydrocephalus patients of mixed aetiology. ${ }^{3}$ To our knowledge only two studies have examined brainstem potentials in hydrocephalic children with spina bifida aperta. ${ }^{45}$

Brainstem auditory evoked potentials have been claimed to be a useful means of assessing the course of hydrocephalus and of predicting the development of symptomatic Arnold-Chiari malformation. The results presented here question such claims.

\section{Patients and methods}

Brainstem auditory evoked potentials were recorded bilaterally from 18 children aged 5 to 17 years. Clinical details were available in 16 and are given in tables 1 and 2 . All had spina

Address for reprint requests: EM Sedgwick, MD, Wessex Neurological Centre, General Hospital, Southampton SO94XY, UK.

*Present address: AG Herbaut, MD, Service de Neurologie, Hôpital Erasme, ULB, Route de Lennick, 8081070 Bruxelles, Belgium.

Received 15 August 1986 and in revised form 28 January 1987. Accepted 30 January 1987 bifida aperta with thoraco-lumbar, lumbar or lumbo-sacral myelomeningocoele closed within 48 hours of birth. Development of hydrocephalus was assessed clinically by measurement of the occipito-frontal head circumference and confirmed by air ventriculography. Holter ventriculo-atrial shunts were inserted at 8 days to 2 months of age in 16 and in one the shunt was removed at 4 months. Two had arrested hydrocephalus and were not shunted. All were paraplegic or paraparetic with urinary and orthopaedic problems. Those with valves had multiple revisions and two had a history of infected valves with meningitis in the past and four developed fits. At the time of recording none had an acute illness or infection nor were there signs of raised intracranial pressure; only one had an upbeating nystagmus as a sign of brainstem dysfunction. None of the children had hearing loss; the hearing threshold tested subjectively was less than $20 \mathrm{~dB}$ in all but one child, in whom it was $25 \mathrm{~dB}$ as a result of frequent middle ear infections. Four additional patients were studied with confirmed hydrocephalus but without spina bifida: two had primary hydrocephalus due to aqueduct stenosis and in two the hydrocephalus was secondary to

Table 1 Clinical data of 5 children with myelomeningocele, with none (.) or one abnormal interpeak latency (> $3 S D$ ). Patients number and sex (male: $M$; female: $F$ ) are related to fig 1 and 2 .

\begin{tabular}{rlll}
\hline Patients & $\begin{array}{l}\text { Myelomeningocele } \\
\text { location }\end{array}$ & Shunt & $\begin{array}{l}\text { Brainstem } \\
\text { sign }\end{array}$ \\
\hline $3 \mathrm{~F}$ & Thoraco-lumbar & No & No \\
$10 \mathrm{~F}$ & Lumbar & Removed & No \\
$1 \mathrm{M}$ & Lumbar & No & No \\
$5 \mathrm{M}()$. & Lumbar & Yes & No \\
$12 \mathrm{M}$ & Lumbar & Yes & No \\
\hline
\end{tabular}


Table 2 Clinical data of 11 children with myelomeningocele, and more than one abnormal interpeak latency ( $>3 S D)$.

Patients number and sex (male: $M$; female: $F$ ) are related to fig 1 and 2 .

\begin{tabular}{clll}
\hline Patients & $\begin{array}{l}\text { Myelomeningocele } \\
\text { location }\end{array}$ & Shunt & $\begin{array}{l}\text { Brainstem } \\
\text { sign }\end{array}$ \\
\hline $4 \mathrm{~F}$ & Thoraco-lumbar & Yes & No \\
$5 \mathrm{~F}$ & Lumbar & Yes & No \\
$6 \mathrm{~F}$ & Lumbo-sacral & Yes & No \\
$7 \mathrm{~F}$ & Thoraco-lumbar & Yes & No \\
$8 \mathrm{~F}$ & Thoraco-lumbar & Yes & No \\
$2 \mathrm{M}$ & Thoraco-lumbar & Yes & No \\
$3 \mathrm{M}$ & Thoraco-lumbar & Yes & No \\
$7 \mathrm{M}$ & Thoraco-lumbar & Yes & No \\
$8 \mathrm{M}$ & Thoraco-lumbar & Yes & No \\
$9 \mathrm{M}$ & Lumbar & Yes & No \\
$11 \mathrm{M}$ & Lumbo-sacral & Yes & Upgaze nyst \\
\hline
\end{tabular}

intracranial haemorrhage at birth. They were shunted at age 3-10 months and were aged 5 to 12 years at the time of recording. Normal data were obtained from a group of age and sex matched healthy children (tables 3 and 4).

A Nicolet pathfinder system was used to record the brainstem auditory evoked potential monaurally following alternating polarity clicks of $100 \mu$ s duration at $9 \cdot 3 \mathrm{~Hz}$ and with an intensity of $70 \mathrm{~dB}$ above hearing threshold. Masking noise at $50 \mathrm{~dB}$ was applied to the other ear. Silver-silver chloride electrodes were applied for recording at the vertex $(\mathrm{Cz})$ and mastoid processes with an earth electrode at $\mathrm{Fz}$ (10-20 system). An amplifier bandwidth of $100-3000 \mathrm{~Hz}$ ( $6 \mathrm{~dB}$ per octave roll off) was used and two separate averages of 2000 sweeps were recorded simultaneously from both sides. Amplitudes, latencies and interpeak latencies were determined from a cursor display and the means and standard deviations of the normal data were determined.

\section{Results}

Tables 3 and 4 give the normal interpeak latency and amplitude values from 30 age matched controls. The brainstem auditory evoked potential was classed as abnormal in all but one of the spina bifida aperta patients. Examples of the types of abnormality are shown in fig 3 . In figs 1 and 2 the interpeak latencies are shown expressed in terms of the standard deviation from the normal mean. Those without spina bifida are indicated by different symbols. Table 5

Table 3 Normal latency values ( $m s$ ) for BAEP in 12 normal males $(M)$ ( 7 to 17 years old) and 18 normal females (F) (5 to 17 years old)

\begin{tabular}{lllll}
\hline & & Mean & SD & Mean $+3 S D$ \\
\hline Wave I & M & 1.602 & 0.089 & 1.869 \\
Wave I & F & 1.539 & 0.107 & 1.860 \\
I-III & M & 2.182 & 0.131 & 2.575 \\
I-III & F & 2.075 & 0.127 & 2.456 \\
III-V & M & 1.838 & $0 \cdot 120$ & 2.198 \\
III-V & F & 1.761 & 0.113 & 2.100 \\
I-V & M & 4.020 & 0.157 & 4.491 \\
I-V & F & 3.839 & 0.168 & 4.343 \\
\hline
\end{tabular}

shows the proportion of patients with different types of abnormal waveforms in terms of latencies and/or poorly formed waves, including decreased amplitude of wave $\mathrm{V}$. The amplitude of wave $\mathrm{V}$ was found to be significantly decreased in males $(p<0.001$, paired $t$ test) but not in females $(\mathrm{p}>0 \cdot 1)$.

Examination of the amplitude and latency of wave I shows it to be normal in every case. The brainstem auditory evoked potential abnormalities are therefore not the result of a peripheral VIII nerve dysfunction. Most abnormalities are of wave III-V interpeak latency $(72 \%)$ indicating the lesion was affecting the higher pons and lower midbrain more than the mid and lower pons. By contrast the brainstem auditory evoked potentials were found to be normal in the four children with hydrocephalus alone.

No correlation was found between the I-V interpeak interval in spina bifida aperta and the delay before insertion of a shunt (correlation coefficient $r=0.1$ (males) and 0.3 (females)). It appears from fig 1 that the $I-V$ interpeak interval is longer in older boys but no statistical correlation was found $(r=0.4)$.

Three children of the four with only one abnormal interpeak latency (table 1) did not need to be shunted or had the shunt removed. All but one of those with thoraco-lumbar defects had more than one abnormal interpeak latency indicating that they were a more severely affected group (table 2 ).

\section{Discussion}

The auditory brainstem pathways in children with spina bifida aperta and long term hydrocephalus are shown to be abnormal in all cases except one $(94 \%)$. Several reasons for this have been proposed and it is important to determine the mechanism as the degree of abnormality of the brainstem auditory evoked potential has been suggested as a means of monitoring hydrocephalus and function of the shunt ${ }^{16}$ and as a sign of presymptomatic Arnold-Chiari malformation. ${ }^{4}$ One possibility is that the abnormalities are the result of increased intracranial pressure. Prolonged III-V and I-V interpeak intervals have been

Table 4 Normal amplitude values ( $\mu \mathrm{s}$ ) for BAEP in 12 normal males $(M)$ ( 7 to 17 years old) and 18 normal females (F) (5 to 17 years old)

\begin{tabular}{lllll}
\hline & & Mean & $S D$ & Mean $+3 S D$ \\
\hline Wave I & M & 0.455 & 0.188 & 0.079 \\
Wave I & F & 0.501 & 0.198 & 0.105 \\
$\begin{array}{c}\text { Wave IV/V } \\
\text { (highest peak) }\end{array}$ & M & 0.573 & 0.152 & 0.269 \\
$\begin{array}{c}\text { Wave IV/V } \\
\text { (highest peak) }\end{array}$ & F & 0.650 & 0.142 & 0.366 \\
\hline
\end{tabular}




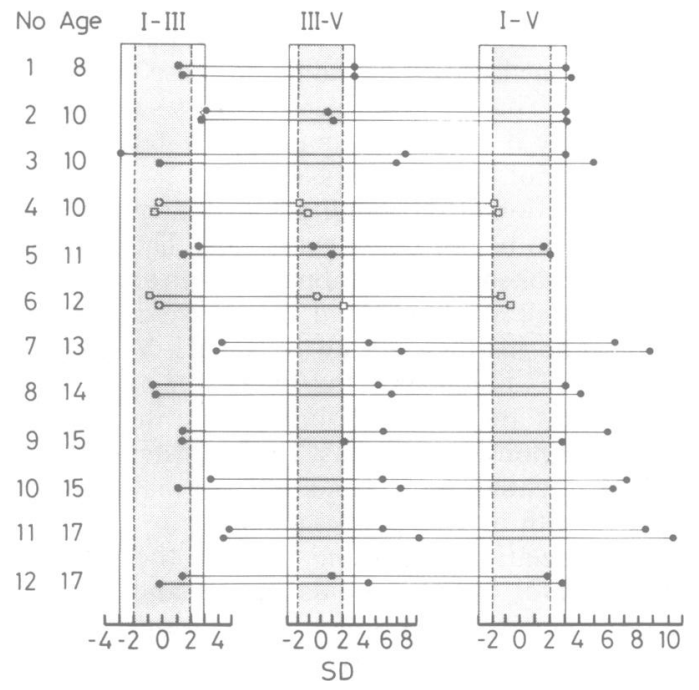

Fig 1 Interpeak latencies of the brainstem auditory evoked potential from both ears of 12 male patients expressed in terms of the standard deviation from the normal mean. $\bigcirc=$ spina bifida aperta patients, $\square=$ hydrocephalus only patients.

observed in experimental and clinical situations with raised pressure ${ }^{48}$ but the abnormalities were transient and resolved when pressure was reduced. This explanation cannot apply to our series of patients who had functioning shunts at the time of the record-

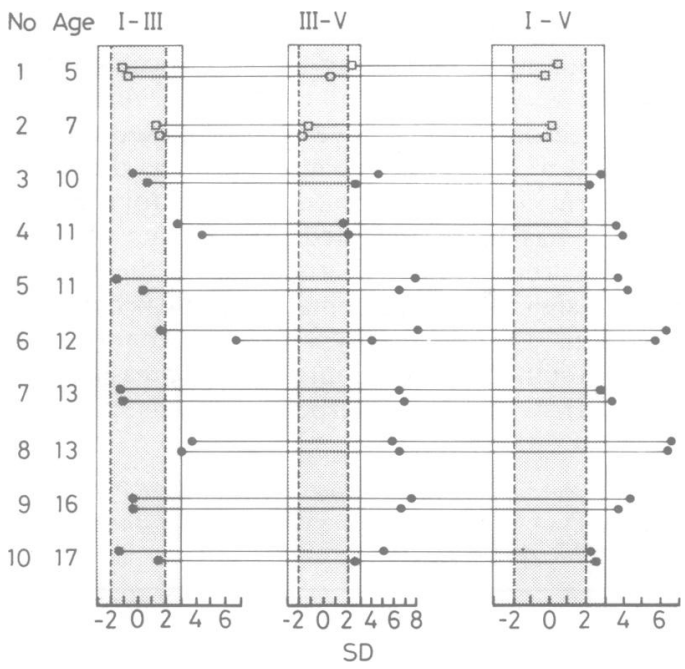

Fig 2 Interpeak latencies of the brainstem auditory evoked potential from both ears of 10 female patients expressed in terms of the standard deviation from the normal mean. $\bigcirc=$ spina bifida aperta patients, $\square=$ hydrocephalus only patients.
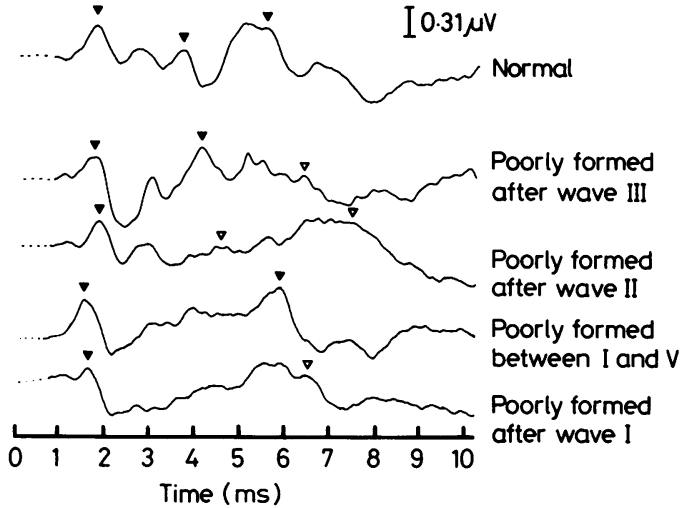

Fig 3 Types of abnormalities of the brainstem auditory evoked potential seen in patients with spina bifida aperta.

$\Delta$ identifies a peak with latency within the normal range

$(<3 S D) ; \triangle$ identifies a peak with an abnormal latency $(\geqslant 3 S D)$.

ing and no evidence of raised intracranial pressure.

It cannot be a residuum from a former episode of hydrocephalus as the four patients with hydrocephalus without spina bifida had normal brainstem auditory evoked potentials.

It has been proposed that alterations in the circulation in the posterior fossa may lead to ischaemico changes which would alter the brainstem auditory evoked potential. ${ }^{3}$ The degree of abnormality would 8 reflect duration of the ischaemic change and would relate to the delay between birth and shunting. The I-V interpeak delays of the brainstem auditory? evoked potential however show no correlation with the time before insertion of a shunt. The cases with hydrocephalus only were all shunted later in life and showed no delays.

Spina bifida aperta is associated with ArnoldChiari type II malformation ${ }^{9-11}$ and hydrocephalus appears in $90 \%$ of these cases, ${ }^{12}$ aqueduct stenosis is also seen. There is no agreement about the precise relationships between these conditions. Spina bifida aperta is believed to be the primary lesion by some ${ }^{13}$ but others ${ }^{913-15}$ claim that spina bifida aperta, Arnold-Chiari malformation and aqueduct stenosis are all manifestations of a developmental dysgenesis of the neuroaxis with a common but unknown cause. It is proposed that the abnormalities are a feature of Arnold-Chiari type II malformation which is present in most, if not all cases of spina bifida aperta. The severity of the deformity increases with the extent of the spina bifida aperta defect ${ }^{41617}$ and may explain why $87.5 \%$ of the cases with thoraco-lumbar defects are associated with higher brainstem abnormalities in our series (table 2). In Arnold-Chiari malformation there is thinning of the lower pons and medulla and 
Table 5 Incidence of abnormal BAEP waveforms in patients with myelomeningocele and hydrocephalus (a) and patients with hydrocephalus only (b)

\begin{tabular}{llllcc}
\hline & $\begin{array}{l}\text { IV and } V \\
\text { abnormal }\end{array}$ & $\begin{array}{l}\text { III, IV and } V \\
\text { abnormal }\end{array}$ & $\begin{array}{l}\text { Only I and } V \\
\text { preserved }\end{array}$ & $\begin{array}{c}\text { All abnormal } \\
\text { after I }\end{array}$ & $\begin{array}{c}\text { Total } \\
\text { abnormal }\end{array}$ \\
\hline $\begin{array}{c}\text { Percent in group (a) } \\
\mathrm{n}=18\end{array}$ & $5 \cdot 5$ & 17 & 22 & $55 \cdot 5$ & 100 \\
$\begin{array}{c}\text { Percent in group (b) } \\
\mathrm{n}=4\end{array}$ & 0 & 0 & 0 & 0 & 0 \\
\hline
\end{tabular}

the pontine flexure is undeveloped; defects of the midbrain are seen with a beak-like deformity of the tectum with fusion of the colliculi, elongation of the rostral part of the tectum and mesencephalon. ${ }^{9} 161819$ These midbrain abnormalities were suggested as the cause of abnormal brainstem auditory evoked potentials recorded in 10 of 15 neonates with Arnold-Chiari malformations. ${ }^{2}$ Further deformation may occur even in children with satisfactory shunts as there is continuing upward growth of the cerebellum which protrudes through the tentorium with rostral movement of the brainstem. ${ }^{20}$ Only two children had CT (fig $4 a, b)$ which showed the associated brainstem malformation demonstrated in various pathological studies. ${ }^{14162021}$

Three of the four children with only one brainstem

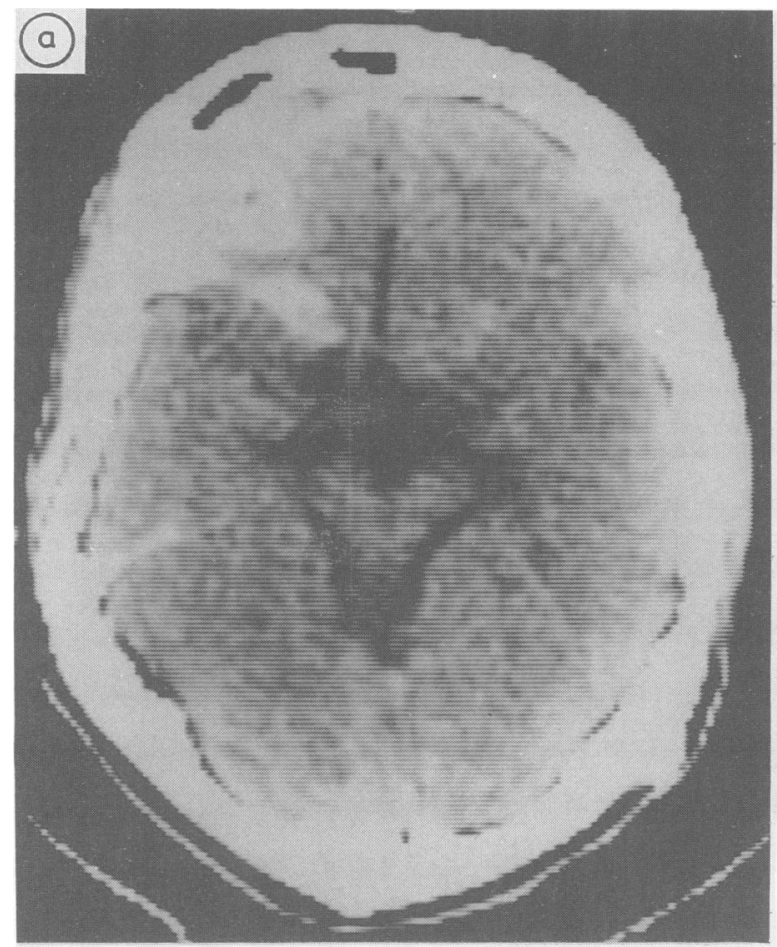

auditory evoked potential abnormality did not need a permanent shunt, possibly because the degree of malformation was mild and hydrocephalus did not develop. These deformities were not seen in the four shunted hydrocephalus-only children whose brainstem auditory evoked potentials were normal. This may be the reason why other studies, which have included hydrocephaly of different aetiologies, have reported smaller percentages of abnormal responses. ${ }^{322}$ It is known that only $20 \%$ of children with myelomeningocoele develop clinical manifestations of Arnold-Chiari type II malformation and that $65 \%$ of these do so in the first 3 months of life. ${ }^{11}$ The question of whether the brainstem auditory evoked potential recorded at this time might be useful in predicting the clinical prognosis of these patients

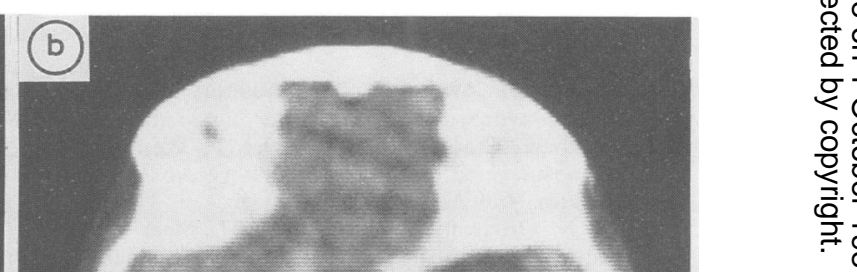


has been raised. ${ }^{4}$ We have followed this group of patients for 3 years. None of the 17 survivors, (one of whom died of pneumonia), have demonstrated neurological signs of Arnold-Chiari malformation. This is in contrast to a recent study ${ }^{5}$ which showed that children with the longest I-V interpeak latencies had clinical signs of Arnold-Chiari malformation at the time of recording $(26 \%)$. It would have been of interest to know if those subjects with lower cranial nerve palsies had more frequent abnormalities in the I-III interpeak interval. In our group the brainstem auditory evoked potential has had no prognostic significance.

The brainstem auditory evoked potential has been proposed as a means of monitoring the effectiveness of a ventriculo-peritoneal shunt. ${ }^{16}$ In patients such as these with abnormal brainstem auditory evoked potentials due to brainstem malformation such a procedure is impractical unless brainstem auditory evoked potentials were recorded at regular intervals, though we would not deny that an abnormal brainstem auditory evoked potential may become even more abnormal with the development of raised intracranial pressure.

\section{References}

1 McPherson DL, Amlie R, Foltz E. Auditory brainstem response in infant hydrocephalus. Childs Nervous Systems 1985;1:70-6.

2 Stockard JE, Stockard JJ, Kleinberg F, Westmoreland BF. Prognostic value of brainstem auditory evoked potentials in neonates. Arch Neurol 1983;40:360-5.

3 Kraus N, Ozdamar O, Heydemann PT, Stein L, Reed NL. Auditory brainstem responses in hydrocephalic patients. Electroencephalogr Clin Neurophysiol 1984;59:310-17.

4 Holliday PO, Pillsbury D, Kelly DL, Dillard R. Brainstem auditory evoked potentials in Arnold-Chiari malformation: possible pronostic value and changes with surgical decompression. Neurosurg 1985;16(1):48-53.

5 Lutschg J, Meyer E, Jeanneret-Iseli C, Kaiser G. Brainstem auditory evoked potentials in myelomeningocoele. Neuropediatrics 1985;16(4):202-4.

6 Edwards CG, Durieux-Smith A, Picton TW. Auditory brainstem response audiometry in neonatal hydrocephalus. J Otolaryngol 1985;14(suppl):40-6.

7 McPherson DL, Blanks J, Foltz E. Intracranial pressure effects on auditory evoked response in the rabbit: preliminary report. Neurosurg 1984;14(2):161-6.

8 Nagao S, Sunami N, Tsutsui T, Honma Y, Doi A, et al. Serial observation of brainstem function by auditory brainstem responses in central transtentorial herniation. Surg Neurol of 1982;17:355-57.

9 Milhorat TH. Hydrocephalus and the Cerebrospinal fluid. Baltimore: Williams and Wilkins, 1972.

10 Nelson WE, Behrman RE, Vaughan VC. Diseases of the nervous system: defects of closure of the neural tube. In: Nelson WE, ed. Textbook of Paediatrics. Philadelphia: WB Saunders Com- $\overline{\bar{N}}$ pany, 1983:1561.

11 Park TS, Hoffman HJ, Hendrick EM, Humphreys RP. Experience with surgical decompression of the Arnold-Chiari $\frac{O}{n}$ malformation in young infants with myelomeningocoele. Neurosurgery 1983;13(2):147-52.

12 Lorber J. Systematic ventriculographic studies in infants born with myelomeningocoele and encephalocoele: the incidence ${ }_{\infty}$ and development of hydrocephalus. Arch Dis Child 1961;36: 381-9.

13 Warkany J, O'Toole BA. Experimental spina bifida and associated malformations. Child's Brain 1981;8:18-30.

14 Brocklehurst G. Congenital malformation of the spine and spinal cord. In: Vinken PJ, Bruyn GW, eds. Handbook of Clinical Neurology. Amsterdam, North Holland, 1978:519-46.

15 Peach B. The Arnold-Chiari malformation. Arch Neurol of 1965;12:527-35.

16 Emery JL, MacKenzie N. Medullo-cervical dislocation deformity $\vec{\circ}$ related to neurospinal dysraphism. Brain 1973;96:155-62.

17 Gunberg DL. Spina bifida and the Arnold-Chiari malformation in the progeny of trypan blue injected rats. Anat $R \Phi \vec{\infty}$ 1956;126:343-67.

18 Masters CL. Pathogenesis of the Arnold-Chiari malformation the significance of hydrocephalus and aqueduct stenose J Neuropathol Exp Neurol 1978;37:56-74.

19 Peach B. Arnold-Chiari malformation: anatomic features of cases. Arch Neurol 1965;12:613-21.

20 Emery JL. Intracranial effects of long-standing decompression the brain in children with hydrocephalus and myelomeni gocoele. Dev Med Child Neurol 1965;7:302-9.

21 Gilbert JN, Jones KL, Rorke LB, Chernoff GF, James HE. Central nervous system anomalies associated with myelomeningocele, hydrocephalus and the Arnold-Chiari malformation: Reappraisal of theories regarding the pathogenesis of posterior neural tube closure defects. Neurosurg 1986;18:559-64.

22 De Vlieger M, Sadikoglu S, van Eijndhoven JHM. Visual evoked potentials, auditory evoked potentials and EEG in shunted hydrocephalic children. Neuropediatrics 1981;12:55-61. 